\title{
Prevalência de aloimunização eritrocitária em pacientes portadores de anemia falciforme
}

\author{
Prevalence of red blood cell alloimmunization in patients with sickle cell anemia
}

Alexandre Gomes Vizzoni ${ }^{1}$, Heladya Maria Matos Moreira

${ }^{1}$ Instituto Nacional de Infectologia Evandro Chagas (INI), Fundação Oswaldo Cruz (FIOCRUZ) - Rio de Janeiro (RJ), Brasil.

${ }^{2}$ Curso de Especialização em Imuno-Hematologia, Universidade Federal do Rio de Janeiro (UFRJ) - Rio de Janeiro (RJ), Brasil.

DOI: http://dx.doi.org/10.7322/abcshs.v42i1.950

\section{RESUMO}

Embora as transfusões de concentrado de hemácias sejam importantes para o tratamento de pacientes com anemia falciforme, elas acarretam riscos imunológicos tais como a aloimunização a antígenos eritrocitários. Aproximadamente $50 \%$ dos pacientes de anemia falciforme recebem transfusões no decorrer da vida, e entre $5 \%$ a 10\% destes pacientes são submetidos a um programa de transfusão crônica. A aloimunização eritrocitária é uma complicação séria da transfusão, mas relativamente comum. Esta condição pode inclusive levar a reações transfusionais hemolíticas tardias e contribuir para aumentar as comorbidades da doença. Importantes medidas para prevenção destas complicações nestes pacientes são o uso de hemácias previamente fenotipadas, além da fenotipagem do próprio receptor de concentrado de hemácias, determinando seu correto perfil fenotípico e possibilitando a escolha de concentrado de hemácias com antígenos correspondentes ao do paciente a ser transfundido. Extensa genotipagem eritrocitária profilática para selecionar doadores para pacientes que receberão repetidas transfusões durante um longo período é uma aplicação atraente de tipagem de sangue baseados em DNA. Isto é, particularmente relevante para pacientes com doença falciforme onde a taxa de aloimunização é elevada.

Palavras-chave: anemia falciforme; formação de anticorpos; eritrócitos; auto-hemoterapia.

\section{ABSTRACT}

Although packed red blood cells transfusions are important for treating patients with sickle cell anemia, this intervention may lead to immunological disturbs, such as alloimmunization by erythrocyte antigens. Approximately $50 \%$ of patients with sickle cell anemia receive blood transfusions during their life span, and about 5 to $10 \%$ of them require a chronic transfusion scheme. The red blood cell alloimmunization is a serious but common transfusion reaction. This condition could lead to delayed hemolytic transfusion reactions, contributing to increase comorbidities of the disease. Important measures to prevent these complications in patients are the use of previously phenotyped red blood cells, in addition to the phenotyping of red blood cells from the acceptor patient, determining the correct phenotypic profile and enabling the choice of red blood cells with corresponding antigens to the patient to be transfused. Extensive prophylactic red blood cell genotyping to select donors for patients receiving repeated transfusions over a long period of time is a compelling application of DNA-based blood typing. This is particularly relevant for patients with sickle cell disease where the rate of alloimmunization is high.

Keywords: anemia, sickle cell; antibody formation; erythrocytes; autohemotherapy.

Recebido em: 27/11/2015

Revisado em: 10/04/2016

Aprovado em: 20/06/2016

Autor para correspondência: Alexandre Gomes Vizzoni - Instituto Nacional de Infectologia Evandro Chagas - Avenida Brasil, 4.365 - Manguinhos CEP: 21040-900 - Rio de Janeiro (RJ), Brasil - E-mail: alexandre.vizzoni@gmail.com

Conflito de interesses: nada a declarar. 


\section{INTRODUÇÃO}

A anemia falciforme (AF) é uma doença que ocorre com mais frequência em negros africanos e pardos, sendo geneticamente determinada pela hereditariedade e etnia ${ }^{1,2}$. Originou-se na África e foi trazida para as Américas, sobretudo pela migração forçada de africanos nativos para o trabalho escravo. Hoje em dia, ela também é encontrada em toda a Europa e Ásia. Por conta da miscigenação da população brasileira, a AF espalhou-se de forma aleatória por todo o país, embora a sua presença seja mais evidente onde a população afro-brasileira é maior ${ }^{3}$.

É a doença hereditária mais comum no Brasil. Ela acontece quando há a substituição da hemoglobina A (HbA) normal, por meio de uma mutação de ponto (GAG>GTG) no gene da globina beta ${ }^{4,5}$. Essa mutação leva à substituição de um ácido glutâmico por uma valina na posição seis da cadeia beta e consequente modificação físico-química na molécula da hemoglobina, originando uma hemoglobina anormal, denominada de hemoglobina $\mathrm{S}(\mathrm{HbS})$. A doença surge em decorrência da homozigose dessa hemoglobina ( $\mathrm{HbS} / \mathrm{HbS})^{2}$.

A AF pode ser responsável por: anemia hemolítica crônica, reações de vaso-oclusão com crises de dor, acidente vascular encefálico (AVE), sequestro esplênico, crise aplástica, priaprismo, síndrome torácica aguda, síndrome do quadrante superior direito e lesões orgânicas progressivas, resultando em insuficiência renal precoce ou tardia, osteonecrose, retinopatia, complicações biliares, falência hepática e hipertensão pulmonar, além de maior susceptibilidade a outras infecções ${ }^{6}$. No Brasil, de acordo com o Ministério da Saúde, acredita-se que existam sete milhões de portadores de HbS. Além disso, 3,5 mil crianças brasileiras nascem com a doença a cada ano ${ }^{2,7}$.

A AF é uma doença inflamatória crônica que pode levar à morte por episódios agudos de AVEs, principalmente na infância. A HbS, sob baixas pressões de oxigênio, sofre polimerização nos eritrócitos, fazendo com que estes assumam a forma de foice. Com esse formato, eles circulam de maneira inadequada na microcirculação, ocasionando obstrução do fluxo sanguíneo capilar, isquemia e infarto tecidual ${ }^{8}$.

O diagnóstico da AF é laboratorial, podendo ser realizado logo após o nascimento, com o teste do pezinho, ou no sexto mês de vida. São feitos testes de solubilidade, conhecidos como testes da mancha, nos quais a HbS é insolúvel em solução tampão inorgânica. São testes rápidos e fáceis de se aplicar, usados em triagem e em casos de emergência. $O$ resultado positivo ocorre com a turbidez da solução, em função da insolubilidade da desoxi-hemoglobina $\mathrm{S}^{9}$. Atualmente, a maioria dos programas de triagem neonatal substituiu os métodos convencionais de eletroforese por focalização isoelétrica e/ou por cromatografia líquida de alta resolução ${ }^{9-11}$.

A terapia transfusional é muito utilizada em pacientes portadores de AF, com o objetivo de melhorar a capacidade de transporte de oxigênio e o fluxo de sangue na microcirculação, diminuindo a porcentagem de $\mathrm{HbS}$ e aumentando o nível de hematócrito, de modo a contribuir para a prevenção de eventos vaso-oclusivos clinicamente importantes ${ }^{5,12,13}$.

A aloimunização eritrocitária dá-se quando um paciente produz anticorpos direcionados contra antígenos das hemácias do doador, considerados como estranhos ao organismo, pois esses antígenos não estão presentes nas hemácias do paciente. Constitui um dos maiores riscos resultantes da terapia transfusional, além de limitar a disponibilidade de concentrados de hemácias que sejam compatíveis para futuras transfusões e também elevar o risco de hemólise ${ }^{14,15}$.

Por isso, é de grande importância a realização de fenotipagem dos grupos sanguíneos, tanto de pacientes portadores de AF quanto dos doadores de sangue, a fim de evitar a aloimunização e, consequentemente, uma possível reação transfusional hemolítica ${ }^{5,16}$.

Os principais sistemas eritrocitários submetidos à fenotipagem são o Rh (antígenos D, C, c, E, e) e o Kell (antígeno K), por serem os que apresentam as maiores frequências de aloimunização em pacientes portadores de $\mathrm{AF}^{5,17}$. Desse modo, pacientes que contêm anticorpos irregulares (anticorpos produzidos após estímulo antigênico por hemácias não próprias) devem receber concentrado de hemácias com fenótipo compatível, com o propósito de evitar reações transfusionais hemolíticas ${ }^{18,19}$.

Em algum momento da vida, 50\% dos portadores de AF recebem transfusões de concentrado de hemácias, e de 5 a $10 \%$ do total desses pacientes entram no programa de transfusão crônica ${ }^{5}$. As transfusões podem ocasionar complicações imunológicas e aloimunizações, com incidência global variando entre 18 e $36 \%$, aumentando assim a comorbidade da doença ${ }^{20}$. Contudo, entre pacientes com AF na Uganda e Jamaica, onde os doadores e pacientes são racialmente mais homogêneos, houve relatos de taxas de aloimunização de apenas 6,1 e 2,6\%, nessa ordem ${ }^{18,21}$

Durante ou após a terapia transfusional, o tratamento é considerado de risco, por conta da possibilidade de reações transfusionais hemolíticas tardias - delayed hemolytic transfusion reactions (DHTR) - , e por se tratar de material biológico ${ }^{14}$.

As transfusões realizadas em pacientes portadores de AF podem acarretar reações transfusionais hemolíticas imediatas ou tardias. A reação hemolítica imediata ocorre no momento em que começa a transfusão, ou em alguns minutos ou horas após seu início (na maioria dos casos acontece por incompatibilidade $\mathrm{ABO}$ entre doador e o receptor da transfusão), enquanto a reação hemolítica tardia se dá em cerca de 48 horas ou em até três semanas após a transfusão, como, por exemplo: reação anamnésica ao antígeno $\mathrm{K}$ por um paciente sensibilizado previamente ${ }^{22}$.

Alves et al. ${ }^{19}$, em um estudo prospectivo sobre aloimunização em pacientes com doenças agudas e/ou atendidos em emergências médicas, descrevem que, quanto maior o número de transfusões feitas, mais o organismo se torna sensível a produzir anticorpos. Eles também ressaltam que os anticorpos dos sistemas Rh e Kell foram os mais encontrados, pelo fato de 
ambos os sistemas conterem antígenos bastante imunogênicos. Adicionalmente, neste trabalho, constatou-se que, mesmo um ano (ou mais) depois das transfusões, alguns pacientes ainda apresentavam determinados anticorpos em seu soro, como o anti-Kell (anti-K). Esse longo tempo de prevalência é reforçado por outros autores, os quais afirmam que os anticorpos do sistema Kell podem permanecer na circulação por até cinco anos ${ }^{23}$.

Em uma pesquisa sobre aloimunização e autoimunização em pacientes com $\mathrm{AF}^{24}$, verificou-se que $20 \%$ deles tiveram aloimunização eritrocitária, sendo a maioria mulheres. Os principais aloanticorpos detectados foram dirigidos contra antígenos dos sistemas Rh, Kell, Duffy e Kidd.

As aloimunizações geralmente acometem pacientes com múltiplas transfusões, o que torna aqueles com AF mais susceptíveis, em virtude de necessitar de várias transfusões ${ }^{25}$. Quanto maior o número de transfusões, maior a possibilidade de exposição a antígenos que não são próprios aos portadores de AF e, consequentemente, maior o risco de aloimunização, segundo alguns autores ${ }^{26,27}$.

A Tabela 1 mostra a frequência de aloimunização nos indivíduos portadores de AF em diferentes populações, contudo sabe-se que a resposta imune a antígenos eritrocitários pode variar de acordo com a etnia, a idade, o número de transfusões e o gênero ${ }^{27-31}$.

Em outro estudo realizado no hemocentro de Uberaba, Minas Gerais, com pacientes politransfundidos, incluindo indivíduos com doenças agudas e crônicas, também foi observado que os anticorpos que exibiram maior frequência foram os que apresentavam especificidade para os sistemas Rh e Kell ${ }^{32}$. Ainda neste trabalho, o sexo feminino predominou entre os aloimunizados, por ser esse gênero normalmente mais sensível a aloimunizações, por causa das gestações, que constituem importante fator de risco de sensibilização ${ }^{27,32}$.

Os antígenos Duffy são carregados por proteínas integrais da membrana de eritrócitos, também conhecidas como receptor de antígeno Duffy para quimiocinas -Duffy antigen receptor for chemokines (DARC). A principal finalidade de tais proteínas é atrair elementos mediadores inflamatórios que atuam sobre os neutrófilos e sobre o endotélio, facilitando a adesão leucocitária. Além disso, o DARC parece ser responsável pela retirada (clearance) da interleucina-8 (IL-8) da circulação, impedindo que esta ative os neutrófilos ${ }^{33}$.

O aumento da segurança transfusional em pacientes politransfundidos pode estar relacionado à fenotipagem eritrocitária precoce, uma vez que transfusões com fenótipo compatível evitariam a aloimunização $0^{5,29,34}$. Como a maioria dos títulos de anticorpos irregulares diminuem com o passar do tempo, reduzindo assim as chances de serem detectados, as transfusões homólogas permitiriam evitar uma resposta imune secundária, ou até mesmo um resultado falso-negativo nos testes pré-transfusionais (prova de compatibilidade, pesquisa de anticorpos irregulares $)^{22,35}$.

As técnicas de biologia molecular são ferramentas bastante utilizadas em casos inconclusivos, em que não se consegue definir para qual(is) antígeno(s) o paciente foi aloimunizado. Pesquisas têm sido direcionadas para a caracterização molecular dos polimorfismos dos grupos sanguíneos, obtendo-se então nova abordagem para a determinação dos antígenos eritrocitários, com base na definição da sequência de DNA em vez da aglutinação ${ }^{36}$. As principais aplicações da genotipagem na medicina transfusional estão relacionadas à tipagem de DNA fetal, tipagem estendida dos diversos sistemas de grupos sanguíneos de doadores para uso em pacientes aloimunizados, determinação do genótipo sanguíneo de um paciente recentemente transfundido, triagem de doadores de sangue para encontrar raros genótipos sanguíneos, identificação da frequência de polimorfismos de grupos sanguíneos em uma população, determinação da zigosidade do antígeno D do sistema $\mathrm{Rh}(\mathrm{RhD})$ para os pais de fetos em risco de doença hemolítica perinatal (DHPN) e tipagem sanguínea de pacientes com anemia hemolítica autoimune ${ }^{37}$.

Tabela 1: Aloimunização em pacientes portadores de anemia falciforme

\begin{tabular}{|c|c|c|c|}
\hline Referência & País & $\begin{array}{l}\text { Frequência de } \\
\text { aloimunização (\%) }\end{array}$ & Especificidade(s) do(s) aloanticorpo(s) \\
\hline Vichinsky et al. ${ }^{26}$ & Estados Unidos & 30,0 & anti-K, anti-E, anti-C, anti-Jkb, anti-Jka, anti-Fya , anti-S, anti-Fy', anti-e, anti-Jka \\
\hline Pinto et al. ${ }^{5}$ & Brasil & 12,7 & Sistemas Rh, Kell, MNS e Lewis* \\
\hline Helman et al. ${ }^{7}$ & Brasil & 22,6 & anti-E, anti-K, anti-Fy ${ }^{\mathrm{a}}$, anti-Jk ${ }^{\mathrm{b}}$, anti-C, anti-Di ${ }^{\mathrm{a}}$, anti-D, anti-Lu ${ }^{\mathrm{a}}$ \\
\hline Natukunda et al..$^{28}$ & Uganda & 6,1 & Sistema Rh e sistema MNS* \\
\hline Kangiwa et al. ${ }^{20}$ & Nigéria & 5,0 & Sistemas Rh, Kell e Duffy* \\
\hline Campbell-Lee et al..$^{15}$ & Estados Unidos & 30,0 & anti-C, anti-E, anti-K \\
\hline Murao \& Viana ${ }^{27}$ & Brasil & 9,9 & $\begin{array}{c}\text { anti-C, anti-D, anti-E, anti-c, anti-e, anti-K, anti-Fy', anti-Le }{ }^{\mathrm{a}} \text {, anti-Jk } \text { anti-Jk }^{\mathrm{a}} \text {, } \\
\text { anti-M, anti-S, anti-P }\end{array}$ \\
\hline Ugwu et al. ${ }^{29}$ & Nigéria & 9,3 & anti-E, anti-C, anti-D, anti-e, anti-k + anti-kp + anti-Js ${ }^{\mathrm{b}}+$ anti-Lub \\
\hline Elenga \& Niel ${ }^{30}$ & Guiana Francesa & 16,0 & 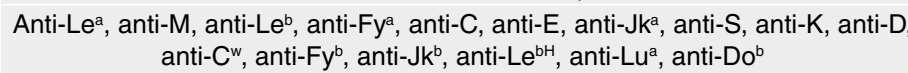 \\
\hline Chou et al..$^{31}$ & Estados Unidos & $15,0^{\dagger}, 58,0^{\ddagger}$ & 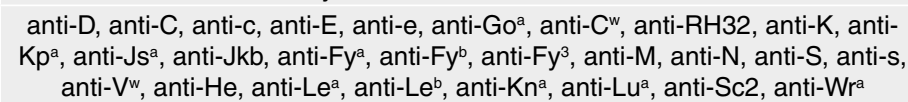 \\
\hline
\end{tabular}

*especificidades dos anticorpos não disponíveis; †pacientes com transfusões esporádicas; łpacientes com transfusões crônicas 


\section{CONCLUSÃO}

A transfusão de sangue continua a ser um dos pilares na gestão do tratamento dos pacientes portadores da AF, contudo pode resultar no desenvolvimento de aloanticorpos para os diversos antígenos eritrocitários. Essa aloimunização predispõe o paciente ao risco de reações transfusionais hemolíticas tardias. Os sintomas da DHTR podem mimetizar complicações graves da doença falciforme e, em alguns casos, até mesmo precipitar crises falcêmicas. Além disso, tais reações talvez se tornem uma complicação grave e potencialmente fatal.

Os anticorpos mais produzidos na aloimunização dos pacientes portadores de AF são dirigidos contra antígenos dos sistemas Rh e Kell, por serem estes considerados os mais imunogênicos.

O estudo dos fenótipos eritrocitários dos grupos sanguíneos em pacientes e doadores de sangue proporciona a comparação da frequência dos genes mais imunogênicos de cada sistema, sendo importante para diminuir o risco de aloimunização, além de estimar a disponibilidade de sangue compatível, especialmente em casos prévios de reação transfusional hemolítica tardia.
A fenotipagem eritrocitária nos pacientes portadores de AF é importante para prevenir uma das principais complicações da terapia transfusional, uma vez que a presença de aloanticorpos e autoanticorpos dificulta a obtenção de sangue compatível e podem ocasionar reações transfusionais hemolíticas agudas ou tardias, aumentando a morbidade da doença.

$\mathrm{O}$ uso de hemocomponentes com fenotipagem dos sistemas $\mathrm{Rh}(\mathrm{D}, \mathrm{C}, \mathrm{c}, \mathrm{E}, \mathrm{e})$ e Kell (K) reduz os casos de aloimunização e de reações transfusionais hemolíticas nos pacientes portadores de $\mathrm{AF}$, em comparação às transfusões de hemácias não fenotipadas.

A utilização da genotipagem eritrocitária na prática transfusional não permite distinguir pacientes com maior probabilidade de produzir aloanticorpos daqueles que não são susceptíveis, entretanto pacientes conhecidos como bons formadores de anticorpos podem ser beneficiados pelo método, proporcionando uma seleção de hemácias mais compatível com o genótipo do paciente, de maneira especial os portadores de AF.

\section{REFERÊNCIAS}

1. Bandeira FMGC, Santos MNN, Bezerra MAM, Gomes YM, Araújo AS, Braga MC, et al. Triagem familiar para o gene HBB*S e detecção de novos casos de traço falciforme em Pernambuco. Rev Saúde Pública. 2008;42(2):234-41. http://dx.doi.org/10.1590/S0034-89102008005000002

2. Silva RA, Souza AVV, Mendes SO, Luz PRG, Medeiros MO. Estudo genético-populacional da doença falciforme a partir de doadores de sangue em primavera do Leste-MT. Biodiversidade. 2012;11(1):108-14

3. Brasil. Ministério da Saúde. Agência Nacional de Vigilância Sanitária. Manual de diagnóstico e tratamento de doenças falciformes. Brasília: ANVISA; 2001. 142p.

4. Stypulkowski JB, Manfredini V. Alterações hemostáticas em pacientes com doença falciforme. Rev Bras Hematol Hemoter. 2010;32(1):56-62.

http://dx.doi.org/10.1590/S1516-84842010005000001

5. Pinto PCA, Braga JAP, Santos AMN. Fatores de risco para aloimunização em pacientes com anemia falciforme. Rev Assoc Méd Bras. 2011;57(6):668-73. http://dx.doi.org/10.1590/S0104-42302011000600014

6. Cançado RD, Jesus JA. A doença falciforme no Brasil. Rev Bras Hematol Hemoter. 2007;29(3):203-6.

http://dx.doi.org/10.1590/S1516-84842007000300002

7. Helman R, Cançado RD, Olivatto C. Incidência de aloimunização eritrocitária em pacientes com doença falciforme: experiência de um centro em São Paulo. Einstein. 2011;9(2):160-4. http://dx.doi.org/10.1590/S1679-45082011AO2003

8. Moreira GA. Repercussões respiratórias da anemia falciforme. J Bras Pneumol. 2007;33(3):18-20 http://dx.doi.org/10.1590/S1806-37132007000300002

9. Figueiredo AKB, Santos FAV, Soares LH, Sousa NDL. Anemia falciforme: abordagem diagnóstica laboratorial. Rev Ciênc Saúde Nova Esperança. 2014;12(1):96-103.
10. Lobo CLC, Bueno LM, Moura P, Ogeda LL, Castilho S, Carvalho SMF. Triagem neonatal para hemoglobinopatias no Rio de Janeiro, Brasil. Rev Panam Salud Publica. 2003;13(2-3):154-9. http://dx.doi.org/10.1590/S1020-49892003000200018

11. Brasil. Ministério da Saúde. Secretaria de Assistência à Saúde. Coordenação Geral de Atenção Especializada. Manual de Normas Técnicas e Rotinas Operacionais do Programa Nacional de Triagem Neonatal. Brasília: Ministério da Saúde; 2002.

12. Chou ST. Transfusion therapy for sickle cell disease: a balacing act. Hematology Am Soc Hematol Educ Program. 2013;2013(1):439-46. http://dx.doi.org/10.1182/asheducation-2013.1.439

13. Natukunda B, Schonewille H, Ndugwa C, Brand A. Red blood cell alloimmunization in sickle cell disease patients in Uganda. Transfusion. 2010;50(1):20-5.

http://dx.doi.org/10.1111/j.1537-2995.2009.02435.x

14. Rodrigues R, Gerônimo DS, Mella Junior SE, Peron MLDF. Aplicabilidade da fenotipagem eritrocitária em doadores voluntários e pacientes politransfundidos. Saúde Pesquisa. 2013;6(3):387-97. http://dx.doi.org/10.17765/1983-1870.2013v6n3p\%25p

15. Campbell-Lee SA, Kittles RA. Red blood cell alloimunization in sickle cell: listen to your ancestors. Transfus Med Hemother. 2014;41(6):431-5 http://dx.doi.org/10.1159/000369513

16. Karafin MS, Denomme GA, Bryant BJ. The future of red blood cell alloimmunization risk reduction. Transfusion. 2015;55(1):220-21. http://dx.doi.org/10.1111/trf.12863

17. Godfrey GJ, Lockwood W, Kong M, Bertolone S, Ray A. Antibody development in pediatyric cell patients undergoing erythocytapheresis. Pediatr Blood Cancer. 2010;55(6):1134-37. http://dx.doi.org/10.1002/pbc.22647

18. Yazdanbakhsh K, Ware RE, Noizat-Pirenne F. Red blood cell alloimmunization in sickle cell disease: pathophysiology, risk factors, and transfusion management. Blood. 2012;120(3):528-37. http://dx.doi.org/10.1182/blood-2011-11-327361 
19. Alves VM, Martins PRJ, Soares S, Araújo G, Schmidt LC, Costa SSM, et al. Alloimmunization screening after transfusion of red blood cells in a prospective study. Rev Bras Hematol Hemoter. 2012;34(3):206-11. http://dx.doi.org/10.5581/1516-8484.20120051

20. Kangiwa U, Ibegbulam O, Ocheni S, Madu A, Mohammed N. Pattern and prevalence of alloimmunization in multiply transfused patients with sickle cell disease in Nigeria. Biomarker Res. 2015;3(26):1-6. http://dx.doi.org/10.1186/s40364-015-0050-3

21. Noizat-pirenne F. Relevance of blood groups in transfusion of sickle cell disease patients. C R Biol. 2013;336(3):152-8. http://dx.doi.org/10.1016/j.crvi.2012.09.011

22. Oliveira LCO, Cozac APCNC. Reações transfusionais: diagnóstico e tratamento. Medicina. 2003;36(2/4):431-38. http://dx.doi.org/10.11606/issn.2176-7262.v36i2/4p431-438.

23. Schonewille $H$, van de Watering LM, Loomans DS, Brand A. Red blood cell alloantibodies after transfusion: factors influencing incidence and specificity. Transfusion. 2006;46(2):250-6. http://dx.doi.org/10.1111/j.1537-2995.2006.00708.x

24. Gomes GG. Avaliação de aloimunização e autoimunização eritrocitária em crianças portadoras de anemia falciforme, indicadas ao regime de hipertransfusão por dopller transcraniano alterado ou acidente vascular encefálico instalado. Monografia (Graduação em Medicina) - Faculdade de Medicina da Universidade Federal da Bahia, Salvador; 2014

25. Yazdanbakhsh K. Mechanisms of sickle cell alloimmunization. Transfus Clin Biol. 2015:22(3):178-81. http://dx.doi.org/10.1016/j.tracli.2015.05.005

26. Vichinsky EP, Earles A, Johnson RA, Hoag MS, Williams A, Lubin B. Alloimmunization in sickle cell anemia and transfusion of racially unmatched blood. N Engl J Med. 1990;322(23):1617-21. http://dx.doi.org/10.1056/NEJM199006073222301

27. Murao M, Viana MB. Risk factors for alloimmunization by patients with sickle cell disease. Braz J Med Biol Res. 2005;38(5):675-82 http://dx.doi.org/10.1590/S0100-879X2005000500004

28. Natukunda B, Schonewille H, Van de Watering L, Brand A. Prevalence and specificities of red blood cell alloantibodies in transfused Ugandans with different diseases. Vox Sang. 2010;98(2):167-71. http://dx.doi.org/10.1111/j.1423-0410.2009.01241.x
29. Ugwu NI, Awodu OA, Bazuaye GN, Okoye. Red cell alloimmunization in multi-transfused patients with sickle cell anemia in Benin City, Nigeria. Nijer J Clin Pract. 2015;18(4):522-6. http://dx.doi.org/10.4103/1119-3077.154204

30. Elenga N, Niel L. Alloimmunization in patients with sickle cell disease in French Guiana. J Blood Transfu. 2015;2015:3. http://dx.doi.org/10.1155/2015/812934

31. Chou ST, Jackson T, Vege S, Smith-Whitjey K, Friedman DF, Westhoff CM. High prevalence of red blood cell alloimmunization in sickle cell disease despite transfusion from Rh-matched minority donors. Blood. 2013;122(6):1062-71. http://dx.doi.org/10.1182/blood-2013-03-490623

32. Martins PRJ, Alves VM, Pereira GA, Souza HM. Frequência de anticorpos irregulares em politransfundidos no Hemocentro Regional de Uberaba-MG, de 1997 a 2005. Rev Bras Hematol Hemoter. 2008;30(4):272-76. http://dx.doi.org/10.1590/S1516-84842008000400008

33. Jens E, Pagliarini T, Novaretti MCZ. Sistema de grupo sanguíneo Duffy: biologia e prática transfusional. Rev Bras Hematol Hemoter. 2005;27(2):110-19. http://dx.doi.org/10.1590/S1516-84842005000200011

34. Lasalle-Williams M, Nuss R, Le T, Cole L, Hassel K, Murphy Jr, et al. Extended red blood cell antigen matching for transfusions in sickle cell disease: a review of a 14-year experience from a single center (CME). Transfusion. 2011;51(8):1732-39 http://dx.doi.org/10.1111/j.1537-2995.2010.03045.x

35. Ryder AB, Zimring JC, Hendrickson JE. Factors Influencing RBC alloimmunization: lessons learned from murine models. Transfus Med Hemother. 2014;41(6):406-19. http://dx.doi.org/10.1159/000368995

36. Castilho L, Rios M, Bianco C, Pelegrino J, Alberto FL, Saad ST, et al. DNA-based typing of blood groups for the management of multiply-transfused sickle cell disease patients. Transfusion. 2002;42(2):232-8.

http://dx.doi.org/10.1046/j.1537-2995.2002.00029.x

37. Anstee DJ. Red cell genotyping and the future of pretransfusion testing. Blood. 2009;114(2):248-56. http://dx.doi.org/10.1182/blood-2008-11-146860 